\title{
Cristología integral y cruz de Jesús: aportes a la teología de la cruz desde Karl Rahner y su "Curso fundamental sobre la fe""
}

\author{
Andrés Mauricio Quevedo Rodríguez
}

Recepción: 20 de diciembre de 2017 • Aprobación: 22 de febrero de 2018

Todo encuentro con el hombre concreto Jesús en su seguimiento siempre singular, que no es imitación, sino siempre llamada individual desde su vida concreta, en la participación del misterio de la vida de Jesús desde su nacimiento hasta su muerte es a la vez, siempre y en todas partes, consagración a su muerte y su resurrección.

(Rahner, 2007, p. 362)

\section{Resumen}

Karl Rahner es uno de los teólogos más importantes del siglo pasado. De hecho, su trabajo acerca de la antropología trascendental ha permitido revisar los lugares comunes de la teología, con el fin de darles nuevos significados. Consecuentemente, a partir de la cristología integral propuesta en el libro Curso fundamental sobre la fe: introducción al concepto de cristiano, este artículo muestra cómo es posible pensar la pasión de Jesús desde una perspectiva que incluya no solo el momento de la muerte, sino el conjunto de su vida. Para lograrlo,

Artículo producto del proyecto de investigación “La teología de la cruz como horizonte crítico hermenéutico de la esperanza: perspectivas y actualización del Principium Crux", desarrollado en la Universidad de San Buenaventura.

Citar como: Quevedo Rodríguez, A. M. (2018). Cristología integral y cruz de Jesús: aportes a la teología de la cruz desde Karl Rahner y su "Curso fundamental sobre la fe". Revista Albertus Magnus, IX(1), 43-63. Doi: https://doi.org/10.15332/s2011-9771.2018.0001.02

** Universidad Santo Tomás. Bogotá, Colombia. ORCID: https://orcid.org/0000-00027915-6491. Correo electrónico: andresmquevedor@gmail.com 
hace un acercamiento biográfico al autor, explica el fundamento de la cristología trascendental y relee la cruz desde esta opción teológica.

Palabras clave: Karl Rahner, cruz, cristología integral, cristología trascendental, teología trascendental.

\title{
Integral christology and the cross of Jesus: Contributions to the theology of the cross from Karl Rahner and his "Foundatios of Christian Faith"
}

\begin{abstract}
Karl Rahner is one of the most important theologians of the last century. In fact, his work about transcendental anthropology has opened new ways to revise theology's common places, aiming to give them new meanings. In consequence, following the integral christology proposed in the book Foundatios of Christian Faith. An Introduction to the Idea of Christianity, this article shows how it would be possible to think the passion of Christ from a perspective that might not only include the moment of his death, but also his life as a whole. To manage this, the text takes a biographical approach about the author, explains the founations of fundamental christology, and re-reads the cross from this theologycal option.

Keywords: Karl Rahner, cross, integral christology, transcendental cristology, transcendental theology.
\end{abstract}

\section{Cristologia integral e cruz de Jesus: contribuições para a teologia da cruz de Karl Rahner e seu "Curso fundamental de fé"}

\section{Resumo}

Karl Rahner é um dos teólogos mais importantes do século passado. De fato, seu trabalho sobre a antropologia transcendental tem permitido revisar os lugares comuns da teologia, com o fim de dar-lhes novos significados. Consequentemente, a partir da cristologia integral proposta no livro Curso fundamental de Fé. Introdução ao conceito de cristianismo. Este artigo mostra como é possível pensar a paixão de Jesus de uma perspectiva que inclui não somente o momento da morte, mas o conjunto da sua vida. Para consegui-lo, o texto faz 
uma aproximação biográfica ao autor, explica o fundamento da cristologia transcendental e relê a cruz desde a opção teológica.

Palavras-chave: Karl Rahner, cruz, cristologia integral, cristologia transcendental, teologia transcendental.

\section{Introducción}

La muerte de Jesús ha sido uno de los temas que más ha llamado la atención a lo largo de la historia del cristianismo. Reflexionar respecto de ella resulta importante en cuanto la interpretación de la Pasión repercute directamente en la noción que se tenga de Dios y en la manera de vivir el discipulado cristiano. Asimismo, la praxis de la fe implica una manera de entender el acontecimiento pascual. En consecuencia, con el correr del tiempo, la llamada teología de la cruz ha conocido múltiples aristas que muestran la riqueza que reside en la diversidad de pensamiento. Esto queda evidenciado con las muchas corrientes que existen: desde las propuestas emanadas de la pasiología hasta las que nacen en el contexto de América Latina (Varone, 1988).

Sin embargo, hay que decir que muchas de dichas teologías comparten una limitación común: se han circunscrito a pensar la muerte de Jesús de manera aislada. Pareciera que gran parte de la tradición cristiana occidental ha enfocado sus ojos, exclusivamente, en los hechos acaecidos en el huerto de Getsemaní, el Gólgota y la tumba vacía. El problema de tal visión estriba en que se abandona la comprensión integral del ministerio de Jesús, el cual empieza desde la encarnación del Logos y se desarrolla a través de su infancia y predicación pública, hasta llegar a la experiencia pascual (Moltmann, 2010).

Como reacción a lo descrito, el presente artículo pretende evidenciar que la propuesta cristológica de Karl Rahner permite repensar el acontecimiento de la cruz en una cristología integral. Por un lado, se ha elegido al teólogo alemán, puesto que, a pesar de las diversas críticas que ha recibido (Moltmann, 1992), su teología tiene todavía mucho por decir en la actualidad, entre otras cosas, porque las líneas generales de ella vieron la luz en medio de una época en la que la modernidad había relegado la vivencia de la fe al cumplimiento privado de ciertas exigencias eventuales y los modelos cientificistas hacían ver la religión como algo propio de gente inculta. Rahner asumió sin vacilación el reto que suponía el giro antropológico en la cultura y lo afrontó con la mayor rigurosidad académica posible sin dejar de lado la vivencia profunda de la espiritualidad. 
No en vano "Rahner está ya, por sí mismo, entre los cásicos de la teología de los que uno sigue aprendiendo incluso cuando considera que debe contradecirlos" (Metz, 2002, p. 122).

Por otro lado, la reflexión se centra mayoritariamente en la sección cristológica del Curso fundamental sobre la fe: introducción al concepto de cristianismo (2007). Según el mismo Rahner, tal libro "parte de la persuasión - e intenta fortalecerla desde sí misma - de que entre una fe sencilla de catecismo, por una parte, y el estudio de todas las ciencias mencionadas $-\mathrm{y}$ algunas más - , por otra, hay un medio de justificación de la fe cristiana con honradez intelectual" (p. 10).

Así las cosas, con el fin de cumplir con el objetivo planteado, este texto cuenta con cuatro momentos diferentes. En primer lugar, se encuentra una presentación general de Karl Rahner y su pensamiento teológico. Posteriormente, hay una exposición de algunos de los puntos principales de su cristología presente en el libro seleccionado. El tercer paso es la presentación de varios elementos que permiten entender la cruz en un marco integral a partir de las intuiciones del teólogo jesuita, en relación con otras apuestas teológicas contemporáneas. Por último, se presenta de manera breve el balance de las posibilidades y los límites del trabajo realizado.

\section{Karl Rahner: el cristiano, el teólogo}

Karl Rahner nació el 5 de marzo de 1904 en Friburgo. En 1922, entró en la Compañía de Jesús, donde fue ordenado como presbítero diez años más tarde. En 1934, adelantó sus estudios de Filosofía de la mano de Margot Honecker y Martin Heidegger. Dos años después fue designado profesor de Teología Fundamental en Innsbruck, Austria. En 1939, trabajó junto a Hans Urs von Balthasar en un proyecto que tenía por mira renovar la teología dogmática a partir de los desafíos que mostraba la época. Sin embargo, dicha labor se vio interrumpida por la incursión del régimen nazi. Tras su participación como perito en el Concilio Vaticano II, su pensamiento teológico traspasó fronteras. Entre 1964 y 1966, reemplazó a Romano Guardini en la cátedra de Cosmovisión Cristiana. Después de un tiempo de docencia en Münster, se trasladó a Innsbruck, ciudad en la que murió en 1984 (Ludlow, 2000).

Entre la extensa lista de libros que escribió, cabe destacar cuatro (Endean, Lehemann, Sobrino y Wassilowsky, 2004): a) Espíritu en el mundo (1939), tesis doctoral en la que hace una relectura de la metafísica del conocimiento finito en Tomás de Aquino; b) Oyente de la palabra (1941); compendio de las lecciones que 
impartió durante un tiempo respecto de la relación existente entre teología y filosofía de la religión; c) Escritos de teología (desde 1954), conjunto de 16 volúmenes en los que trata diversos temas de la dogmática cristiana; d) Curso fundamental sobre la fe: introducción al concepto de cristianismo (1976), recopilación de su enseñanza en la clase llamada Introducción al concepto del cristianismo durante el tiempo de docencia en Münster. En esta obra, escrita hacia la última parte de su vida, Rahner sintetizó la búsqueda de su quehacer teológico, es decir, el "esfuerzo del concepto" (2007, p. 9). Su intención con el curso fue presentar las bases epistemológicas necesarias para que sea posible abrazar la fe con honestidad intelectual, por lo cual se enfoca en los fundamentos de algunos de los principales temas teológicos, como, además del de Cristo, la antropología teológica, la Revelación, la Iglesia y la culpa.

El pensamiento de Rahner hunde sus raíces en campos de los más variados. A nivel teológico, se acerca de manera crítica tanto a la Sagrada Escritura como a la Tradición. En cuanto a la primera, es cierto que en sus escritos no abundan citas bíblicas directas, pero esto obedece al rechazo que el autor tiene hacia aquellas reflexiones que acomodan a su conveniencia el sentido real del texto sagrado. Respecto de la segunda, es un gran conocedor de la teología de los Padres de la Iglesia y de los maestros de la escolástica. Su espiritualidad es alimentada por los escritos de Teresa de Ávila, Juan de la Cruz e Ignacio de Loyola (Metz, 2013).

A nivel filosófico, sus principales influencias son Kant, Hegel y Heidegger. Rahner no hace filosofía, pero retoma de ella intuiciones a las que va a dar un sentido novedoso a partir de la fe. Retoma la idea kantiana de entender la trascendentalidad como la estructura interna por la cual era posible conocer los objetos presentes en el mundo, pero da un paso más allá al afirmar que el ser humano no solo está abierto al misterio sagrado. Efectivamente, el misterio es el origen y fundamento del ser humano con su libertad y capacidad de conocimiento, razón por la cual preguntarse por Dios es evidencia de la noción que se tiene de Él. Adopta parte de la visión de Hegel al establecer la conexión entre Creador y Creación basado en la alteridad divina. Con todo, el punto de partido de Rahner es la plenitud y la posibilidad absoluta de Dios para entrar en relación con alguien más. De Heidegger hereda, entre otras cosas, la relación que permite una unión permanente de teología (para el filósofo será la metafísica) y antropología (Kilby, 2004).

A la luz de lo anterior, resulta valioso reconocer las cuatro grandes líneas en torno a las cuales gira el pensamiento de Rahner. Primero, la analogía como el único lenguaje teológico posible debido a la naturaleza propia de Dios: la experiencia trascendental de Dios no puede expresarse adecuadamente en el lenguaje categorial (histórico). Segunda, la autocomunicación de Dios presentada como 
el centro de la teología: la palabra humana que habla del Misterio es siempre un acto segundo, un acto de respuesta ante aquel primer movimiento proveniente de Dios por el cual Él ha dado a conocer lo que es. Tercera, la necesidad que tiene la teología de entrar en diálogo con otras disciplinas: el pensamiento actual está transido por el secularismo y las nuevas posibilidades de conocimiento, razón por la cual la teología debe salir del anquilosamiento en el que se ha sumido. Cuarta, la espiritualidad ignaciana: la teología de Rahner es considera mística en el sentido de que, apoyada en los ejercicios espirituales, afirma la posibilidad de tener una relación de inmediatez con Dios (Gibellini, 1998).

La experiencia trascendental es uno de los ejes temáticos que atraviesa todo el método de Rahner. Gracias a ella es posible que el conocimiento de Dios se manifieste, no como el acercamiento intelectual a un objeto cualquiera, sino como la vivencia más originaria de Dios, que es la esencia misma de la trascendencia (Berríos, 2004). Por un lado, se constituye experiencia en cuanto es un saber no temático que en sí mismo es condición de posibilidad para cualquier otra experiencia del ser humano. Por otro, lo trascendental está dado en virtud de que dicha experiencia hace parte de la estructura interna del sujeto. La trascendentalidad entonces hace referencia a las condiciones con que el ser humano cuenta y que, al presentarse en su existencia como a priori, lo hacen abrirse a aquello que Dios quiere comunicar. De la misma manera que la gracia divina precede y presupone la naturaleza, el acontecimiento de la autocomunicación divina precede y presupone que haya en el receptor la capacidad de aceptar el mensaje (Endean et al., 2004).

\section{La cristología trascendental: una cristología}

Se escapa al propósito del presente artículo exponer en detalle la cristología de Rahner. Sin embargo, es menester esbozar sencillamente algunos elementos que permitan adquirir una comprensión global del pensamiento del teólogo jesuita. Por lo mismo, este segundo título cuenta con tres subtítulos: "Preliminares", que ofrece ideas generales para la reflexión; "Cristología trascendental”, donde se relaciona la teología trascendental con la cristología; y "Salvador absoluto", el cual recoge los puntos más importantes de lo que el autor entiende por tal categoría.

\subsection{Preliminares}

"Llegamos ahora a lo simplemente cristiano del cristianismo, a Jesucristo" (Rahner, 2007, p. 214). Así empieza Rahner el sexto grado de su Curso fundamental 
sobre la fe. Y es que hablar de Jesús, reconocido y aceptado en la fe como el Cristo es referirse al eje fundamental y diferenciador de la experiencia cristiana. La reflexión sobre el Logos encarnado es esencial en cuanto de Él se afirma que es la revelación plena de Dios, lo cual se entiende en dos sentidos. Primero, el sentido teológico: el ser humano alcanza el conocimiento de Dios gracias y por medio de Cristo. Ocurre un cambio de perspectiva, ya que no es que el ser humano conozca a Cristo por creer en Dios, sino que conoce a Dios por tener acceso a Cristo. Segundo, el antropológico: en Cristo el ser humano conoce lo que él es respecto del misterio inefable de Dios.

El capítulo, que es el más largo de todo el libro, tiene por propósito establecer las condiciones de posibilidad que le permiten al ser humano escuchar y relacionarse con el mensaje que se manifiesta en el Dios-hombre. Conforme a esta intención, Rahner clarifica que su disertación no se limita a exponer la doctrina católica. Más bien, su pensamiento se desarrolla a la luz de la necesidad de poner en diálogo la fe en Cristo con los diferentes sistemas de pensamiento nacidos de la modernidad:

Se trata, pues, en primer lugar simplemente de la pregunta sobre la demostración de la posibilidad de acomodar un enunciado a un complejo de otros enunciados, de horizontes de inteligencia, de persuasiones y no de enunciados sobre esto o lo otro por sí solo. (Rahner, 2007, p. 216)

Para lograr su cometido, articula sus postulados alrededor de dos opciones metodológicas, a saber: la implicación existencial de las afirmaciones de fe y la integración entre cristología ascendente y descendente.

A juicio del autor, es insuficiente responder a la pregunta de quién es Jesús. El hecho de esclarecer por diferentes medios la personalidad y naturaleza de Cristo no implica una influencia directa de tales postulados en la vida del creyente. Al contrario, aísla la figura del Redentor al convertirlo en un objeto más del conocimiento humano. En contraste, la pregunta que se debe intentar responder está referida a quién es Jesús para el ser humano concreto, ya que, "por una parte, no nos ocuparíamos de Jesús si él no tuviera ninguna 'significación para nosotros' y, por otra, toda afirmación sobre la significación para nosotros es una afirmación de un 'en sí'”' (p. 245). Efectivamente, ella tiene dos momentos que se relacionan internamente: esclarece la figura de Cristo y la coloca en relación con el devenir histórico humano. Al ampliar la idea, no es desfasado sostener que toda formulación dogmática ha de tener una afectación en la persona.

El teólogo alemán reconoce que los muchos modelos de cristologías se han enmarcado, o bien en una dinámica desde abajo, empezando por un acercamiento 
al Jesús histórico hasta llegar al Cristo de la fe (cristología ascendente); o bien desde arriba, comenzando con la reflexión sobre la preexistencia del Logos y su posterior encarnación en el Jesús histórico (cristología descendente). Esto ha llevado a una polarización en la disciplina que no es del todo adecuada. Por eso, la metodología rahneriana integra ambas cristologías. En lo ascendente, la fe cristiana es justificada a causa del reconocimiento del Jesús histórico como paso previo a la idea de encarnación de Dios como punto de llegada. En lo descendente, la afirmación y confesión de Cristo lleva implícitamente la realidad de la inserción de Dios en la historia humana (Schickendantz, 2004).

\subsection{Cristología trascendental}

La cristología de Rahner se entiende como parte de su propuesta de teología trascendental. Consecuentemente, la pregunta por las condiciones de posibilidad que el ser humano tiene para recibir el mensaje de Cristo no es algo que deba pasarse por alto. La importancia de tal cuestionamiento queda justificada en el hecho de que, si se llegase a ignorar, se corre el riesgo de "valorar las afirmaciones de la teología tradicional simplemente como exaltaciones mitológicas (en el mal sentido) de sucesos históricos, o de no poseer ningún criterio por medio del cual pueda distinguirse, de acuerdo con la cristología tradicional, entre auténtica realidad de la fe, por una parte, y su interpretación, por otra" (2007, p. 248).

Pero la relevancia que tiene la cristología trascendental no la exime de que se esgriman en contra de ella algunas objeciones. El mismo Rahner señala tres límites fácilmente identificables (p. 247): a) historicidad: la relación con Jesús, además de la dimensión trascendental, debe contar con el ámbito histórico del creyente; b) condición aposteriorística: al ser una reflexión que ocurre como segundo momento del acto de fe, presupone la comprensión de nociones que fundamentan dicha fe; c) problema especulativo: resulta muy difícil, acaso imposible, dar crédito a la especulación frente a los enunciados relacionados, por ejemplo, con la Encarnación o la Resurrección.

Ahora bien, siendo consciente de los cuestionamientos mencionados y tratando de resolverlos, el teólogo jesuita sintetiza lo que entiende por cristología trascendental en cinco ideas principales (Rahner, 2007, pp. 250-251):

a. El ser humano es un ente dotado de tensión hacia lo trascendental, lo cual hace que cada acto categorial se dirija hacia el misterio inabarcable.

b. El misterio sagrado, Dios, se autocomunica al ser humano, pero no en el sentido de una manifestación de verdades, sino como la donación de sí mismo. 
c. La autocomunicación de Dios se desarrolla por medio de lo categorial, razón por la cual se puede afirmar la existencia de una mediación histórica.

d. La donación de Dios trae consigo la consumación de la historia, la cual debe ser entendida como relacionada con el concepto de irrevocable y no de acabada.

e. Solo el Salvador absoluto puede lograr hacer presente la irrevocabilidad de la historia.

Al hablar de la cristología de la trascendental, es necesario tocar uno de los puntos más distintivos y conocidos de ella: el cristianismo anónimo. Dicha tesis es la expresión de la radicalidad con la que Rahner asume la cuestión de la salvación de los no cristianos. Reconoce dos características de la autocomunicación trascendental de Dios (Bueno de la Fuente, 1984). Por un lado, es una condición existencial, esto es, una permanente donación de Dios a la existencia particular de cada ser humano. Por otro, reconociendo que es un momento de aquella autocomunicación que libremente Dios ha querido realizar hacia el mundo, tiene como punto de llegada la persona del Hijo.

La estructura teológica rahneriana permite que sea válido afirmar que tanto la revelación de Dios como el encuentro con Cristo se realiza en un primer momento en lo trascendental (en el interior del ser humano, por las condiciones de posibilidad que él tiene) y solo posteriormente en lo categorial (confesión explícita del cristianismo). Por su misma esencia, el nivel trascendental está dado para todo hombre y mujer de manera gratuita, ya que su fundamento es la autocomunicación de Dios. Por tanto, aunque alguien no haya hecho una relación concreta involucrando en su historia personal la fe que sostiene la Iglesia, puede ser cristiano, aunque anónimo, siempre y cuando exista en él la opción de hacerse cargo sin reservas de sí mismo y de su existencia:

En el curso de nuestras reflexiones hemos tenido que acentuar con mucha frecuencia que se da y debe darse una relación en cierto modo anónima y, sin embargo, real del hombre particular con la historia concreta de la salvación, y en consecuencia también con Jesucristo, en aquel que no ha hecho todavía la experiencia entera, concreta, histórica, explícita y reflexiva en la palabra y el sacramento con esta realidad históricosalvífica, sino que solo posee la relación existencialmente real de manera implícita en la obediencia a su referencia gratuita al Dios de la autocomunicación absoluta, la cual se hace presente históricamente, por cuanto este hombre asume sin reservas su existencia, y la asume en aquello que no puede pasar desapercibido ni administrarse en el riesgo de la libertad. (Rahner, 2007, p. 357) 
Pero el cristianismo anónimo no se limita a ser parte de una experiencia interna, sino que encuentra su manifestación más clara en el amor al prójimo (Metz y Rahner, 1979). Si todo ser humano es portador de la autodonación de Dios, entonces cada acto que se realice hacia otro está referido, en último término, a ese Dios que se revela. De hecho, la relación del ser humano con Dios es tan estrecha que el mismo evangelista coloca en boca de Jesús una expresión que la deja ver tu toda su radicalidad: "lo que habéis hecho al menor de mis hermanos, me lo habéis hecho a mí" (Mt 25, 40). Por eso, no es descabellado pensar que "el hombre a quien Cristo no ha alcanzado todavía en el testimonio histórico explícito [...] puede encontrar, sin embargo, a Jesús en su hermano y en el amor a él, en el cual Jesucristo se deja encontrar por así decir anónimamente" (Rahner, 2007, p. 363).

\subsection{El salvador absoluto}

El actuar de Jesús fue un actuar profético: sus hechos y palabras sirvieron para identificarlo como el portador de un mensaje particular. Empero, no fue un profeta como los demás. De hecho, el cristianismo no ve en Jesús una palabra entre otras palabas, sino que sostiene que el nazareno es la Palabra dicha una vez para siempre. Al ser la encarnación del Logos mismo de Dios, su hablar, lejos de ser algo transitorio o superable, es el culmen de todo el lenguaje divino. Entonces, "una acción absoluta (escatológica) de la salvación debe, por tanto, tener una relación realmente distinta con Dios que las demás acciones salvíficas de Dios en la historia todavía abierta de la salvación" (p. 351).

Por Salvador absoluto, Rahner entiende a "aquella personalidad histórica que, apareciendo en el espacio y el tiempo, significa el principio de la autocomunicación absoluta de Dios que llega a su fin, aquel principio que señala la autocomunicación para todos como algo que acontece irrevocablemente y como inaugurada de manera victoriosa" (p. 233). Es necesario aclarar que el atributo de principio no se debe entender en sentido temporal, es decir, como si solo con el advenimiento del Salvador hubiera comenzado la autocomunicación de Dios. De hecho, el teólogo alemán reconoce que, al ser paralela a la historia humana, la Revelación aconteció también antes de la Encarnación del Logos. Por eso, la cualidad de principio debe entenderse como una expresión de la fe que cree que el Salvador es irrevocable, cognoscible y punto cimero.

La categoría mencionada permite responder de alguna manera a la inquietud que el autor manifiesta en varios lugares de su libro respecto de la posibilidad de la existencia del Dios-hombre. En perspectiva cristiana, la plenitud de la donación de Dios no podía ser simplemente un acto específico que el Creador 
realizara de manera externa en lo creado. Por el contrario, la autocomunicación debía encontrar asidero en un trozo mismo del cosmos, debía ser un momento en la historia humana para que así pudiera plenificarla desde su interior. Esto lleva a reconocer a Jesucristo como verdadero hombre en toda su radicalidad. Creer que Jesús, en palabras de Pablo, nació de una mujer (cf. Gal 4,4) implica aceptar que Él, como cualquier ser humano, "recibe aquella comunicación gratuita de Dios mismo que afirmamos en relación con todos los hombres y el cosmos entero como el punto cumbre de la evolución en la que el mundo llega absolutamente a sí mismo y absolutamente a la inmediatez con Dios" (p. 235).

Pero la comprensión de Jesús como salvador absoluto no es meramente un enunciado teórico que nada tiene que ver con la existencia de la persona. Al contrario, la categoría rahneriana permite establecer una vía de conexión eficaz entre lo humano y lo divino: Jesucristo queda constituido como el puente entre Dios y cualquier ser humano, incluso de quien no confiese un credo específico. Pero quien toma conciencia de Jesús como el mediador que hace posible la inmediatez con Dios abre su vida para acoger de manera explícita la fe cristiana. Tal toma de conciencia se realiza por medio del encuentro con Cristo a través de su palabra y la acción divinizante y reconciliadora de su muerte y Resurrección (p. 245).

\section{La cruz: un momento de la cristología}

A partir del camino recorrido, es posible ahora esbozar para el lector algunos elementos que permitan pensar una teología de la cruz dentro de una cristología integral. Estos elementos, enraizados en el pensamiento teológico de Rahner evidenciados en el Curso fundamental sobre la fe, pueden convertirse en los andamios sobre los que se construyan posteriores reflexiones. De ahí que se establezcan, al mismo tiempo, relaciones con el trabajo de otros autores.

\subsection{Historia trascendental}

Aunque en ciertas ocasiones pueda parecer lo contrario, Rahner desecha por entero de su teología el dualismo tanto en su comprensión de la historia como en la manera en la que entiende al ser humano. La diferenciación entre lo trascendental y lo categorial no pretende expresar la existencia de una realidad mundana y una celeste. Más bien, quiere mostrar la relación estrecha que tienen dos dimensiones de una única realidad. Lo trascendental, que se presenta como necesario en cuanto es fundamento, se encuentra íntimamente unido a lo categorial, que es 
lo condicionado concretamente en la historia. En palabras del autor: "Lo trascendental es siempre una condición interna de lo histórico mismo y lo histórico, a pesar de su posición libre, funda juntamente la existencia como tal" (p. 249). Por eso, no puede haber entre ambas algún tipo de reducción o exclusión.

Consecuentemente, Rahner entiende la historia en perspectiva evolutiva, es decir, interrelacionada por la materia, el ser humano y la vida. Pero su pensamiento va más allá, hasta el punto de descubrir en ella una fuerza motriz que la empuja hacia la consumación, hacia la inmediatez de la creación, especialmente del ser humano, con el Creador: "Tal historia una no excluye diferencias esenciales, sino que las incluye en su concepto, pues precisamente la historia no es la permanencia de lo mismo, sino el devenir de lo nuevo, el devenir de un 'más' y no simplemente de lo otro" (p. 225). Este es precisamente su fin, entendido aquel como finalidad y no como punto de terminación: la inmediatez de la autocomunicación de Dios. Precisamente, la acción dinamizadora e interna de Dios posibilita que el mundo se autotrascienda a sí mismo para que así se encuentre con el misterio que le circunda y fundamenta. Así, la historia no está abocada al devenir sin sentido, ya que su telos descansa sobre la acción del Dios que se dona a la humanidad a la espera de ser acogido por ella (Metz, 2002).

\subsection{Antropología trascendental}

La complejidad que encierra el ser humano hace que sea imposible ofrecer una definición de él, razón por la cual habrá que decir que cada persona es ante todo un misterio. Pero para el teólogo jesuita la categoría misterio tiene una connotación especial. A lo largo del Curso fundamental sobre la fe, Rahner advierte que el misterio no es aquello que no se puede conocer o entender, sino que es lo inabarcable, lo incontenible. Al ser un misterio para sí mismo, el ser humano es también misterio en referencia a Dios:

El hombre en su esencia, en su naturaleza misma, es el misterio, no porque sea la plenitud infinita del misterio en sí que le afecta, la cual es inagotable, sino porque él en su esencia auténtica, en su fundamento originario, en su naturaleza es la pobre - pero llegada a sí misma - referencia a esa plenitud. (p. 258)

El misterio que es el ser humano se concretiza en los dos elementos que lo componen: la materia y el espíritu. Para Rahner, el primer componente es la condición de posibilidad de la relación inmediata con los demás seres que existen paralelamente en la historia, mientras que el segundo es la experiencia que hace el 
ser humano de sí mismo (2007, p. 222). El mencionado rechazo al dualismo lleva a Rahner a buscar nuevas formas de adopción de la realidad humana. Reconoce que, a pesar de las múltiples diferencias que hay entre todos los elementos que conforman la naturaleza, en ella hay una unidad garantizada por el hecho de ser obra creada por Dios. Por lo mismo, si lo diverso y lo multiforme no se excluyen mutuamente, la dimensión material y espiritual del ser humano tampoco lo deben hacer (Ruiz de la Peña, 1996).

Por último, es valioso subrayar el papel que desempeña la libertad en la antropología trascendental. Como se señaló, el ser humano, en cuanto es un elemento integrador del cosmos, se descubre dinamizado hacia la inmediatez con la autocomunicación de Dios. Este proceso no se desarrolla de manera forzada e imparable. Existe una correspondencia entre la libertad que mueve a Dios a autocomunicarse al mundo y la libertad con la que el ser humano se relaciona con tal autocomunicación. Frente a la manifestación divina, que es al mismo tiempo permanente y gratuita, cada persona está en la capacidad, ya sea de mostrar aceptación, lo cual desembocaría en la justificación del individuo, ya sea de mostrar rechazo, que se expresaría en la incredulidad o el pecado: "Hemos acentuado siempre que esa comunicación divina existe con necesidad bajo el modo de un previo estar dado en sí y para la libertad, o bien bajo el modo de aceptación (llamada generalmente justificación), o bien bajo el modo de repulsa (llamada incredulidad, pecado)" (p. 233).

\subsection{Articulación de las etapas de la vida de Jesús}

La historia de Jesús cuenta con cuatro etapas: Encarnación, ministerio prepascual, muerte y Resurrección. Entre ellas existe una relación de dependencia tal que lo que se afirme en una afectará la comprensión de las otras tres. Por eso, la adecuada articulación de estos momentos ha de considerarse como primordial en la construcción de una cristología.

\subsubsection{Encarnación}

El esfuerzo por el concepto y la búsqueda por la honestidad intelectual llevan a Rahner a preguntarse por las condiciones de posibilidad de la encarnación del Logos, sobre todo para evitar interpretaciones mitológicas del dogma. El punto de partida, una vez más, es la conciencia de que el ser humano cuenta en su estructura interna con un llamado que lo mueve a alcanzar la plenitud de lo infinito. Este llamado, además de ser posibilitado por Dios y sostenido por su 
gracia como existencial, cuenta con una dimensión activa en la que la persona es protagonista. La tensión entre lo divino y lo humano se presenta entonces como permanente en cuanto cualquier persona se encuentra referida de una $u$ otra forma hacia el encuentro con el misterio sagrado. Dicho esto, se puede pensar con el autor que "la encarnación se presenta como el principio necesario y permanente de la divinización del mundo en conjunto" (p. 220).

Ahora bien, no se puede entender la esencia de la Encarnación de manera aislada a todo el proceso de autocomunicación de Dios (Abdelmalak, 2016). Ya en el acto creador, aunque de manera parcial, el Padre salía de sí mismo, hablaba, por medio de su Logos. Esta primera forma en la que Dios asume lo diferente a su naturaleza recorre un camino histórico que desemboca en su punto culmen con la ocurrencia del advenimiento del Logos al mundo. En consecuencia, la Encarnación no es un suceso por el cual se yuxtapone una realidad divina en medio de la realidad humana. Por el contrario, la Encarnación, al estar relacionada de manera muy cercana al constante proceso creativo de Dios, llega a ser una etapa más de la consecución de momentos por la que el misterio absoluto se autocomunica al ser humano (p. 237).

¿Cómo es posible que Dios, de quien se afirma el carácter de inmutabilidad, llegue a devenir en lo que no es Él mismo? En otras palabras, ¿cómo el Infinito y Eterno puede llegar a constituirse en lo finito y temporal sin anularse? La solución al problema se desencadena a partir de los elementos presentes en la antropología trascendental y su descripción del ser humano como misterio. El hecho de que Dios se torne en carne humana no implica que se haga algo cien por ciento diferente de Él. La Encarnación es pensable en virtud de la analogía que existe entre el misterio de Dios y el del ser humano. En el Logos encarnado, se halla la respuesta que Dios le da a la pregunta humana por su identidad: "Cuando Dios quiere ser no-Dios, surge el hombre" (p. 267).

El misterio infinito no colapsa ante la Encarnación, ya que este acto de autoalienación, más bien, conlleva la plenificación del misterio finito de la persona. Aquí ha de recordarse lo dicho acerca de la verdadera condición humana que adoptó el Salvador absoluto. En este sentido, el dogma de la Encarnación significa que "Dios es verdaderamente hombre con todas sus implicaciones, con su finitud, mundanidad y materialidad, con su participación en la historia de este cosmos en la dimensión del espíritu y de la libertad, en la historia que conduce a través del desfiladero de la muerte" (p. 237). 


\subsubsection{Ministerio prepascual}

El cambio de pregunta mencionado en los preliminares del segundo título de este artículo desemboca en la inquietud por la forma en que el creyente se responsabiliza de su fe en Jesús. La respuesta a este interrogante compone dos dimensiones específicas, a saber, la historicidad, que es acercarse a la identidad del Jesús histórico, y la significación, entendida como el descubrimiento de dilucidar las implicaciones que tiene la persona de Jesús en la existencia del creyente. Pero es evidente que hay una disparidad entre ambas dimensiones. Efectivamente, los estudios críticos de los textos neotestamentarios dejan ver que es muy poco lo que se sabe acerca del Jesús histórico (Piug, 2006), sin embargo, el cristianismo exige una entrega total a este hombre que resulta estar velado tras las cortinas del desconocimiento.

Son claras las dificultades de fijar como exactas muchas de las afirmaciones que se refieren al nazareno. Con todo, tal dificultad no exime que se tome en serio la dimensión histórica de Jesús. Y esto no solo porque la historicidad es un rasgo fundamental en la vida de cualquier ser humano, sino porque el Nuevo Testamento entiende a Cristo como un suceso histórico concreto y no como el resultado exclusivo de un proceso interpretativo posterior a la Resurrección (Rahner, 2007, p. 281). Es necesario que se revalorice entonces tanto la vida privada (Saldaña, 2013) como el ministerio público de Jesús (Ratzinger, 2008), para que así se le comprenda como un ser humano libre y responsable que tomó opciones contundentes ante el cumplimiento de lo que reconocía como su misión, es decir, la predicación del Reino de Dios.

Por tanto, las pocas seguridades que existen acerca de Jesús prepascual son herramientas fundamentales en el proceso de acercamiento y adhesión existencial a Él. Se pueden afirmar principalmente cinco cosas del Jesús histórico:

a. Convivió naturalmente con el entorno religioso en el que se encontraba y cumplió los preceptos que el judaísmo de su tiempo tenía.

b. Fue un reformador religioso radical que se enfrentó contra la interpretación legalista de la religión y luchó por establecer una ética que fuera más allá de las actitudes piadosas externas.

c. Aunque esperó que su ministerio tuviera éxito, descubrió progresivamente que el choque con el poder religioso y político de la época se convertía en una amenaza para su vida.

d. Tuvo al Reino de Dios como el centro de su predicación y quiso congregar alrededor suyo a personas que se adhirieran a su mensaje.

e. Aceptó la muerte impuesta por las autoridades de la época como signo de fidelidad a la misión que le había sido encomendada por Dios. 


\subsubsection{Pasión y muerte}

Las ideas mencionadas respecto del Jesús prepascual permiten redimensionar el acontecimiento de su muerte en la cruz. Sentirse parte esencial de la misión concreta del Reino hace que prevea su muerte como consecuencia lógica de un actuar profético marcado por el anuncio y el denuncio. Así lo dejan ver los textos evangélicos cuando, por ejemplo, narran la manera en que el Maestro huye de las autoridades o cuando los jefes judíos planean la forma de arrestarlo. Evidentemente, la Buena Noticia de la que Jesús era portador llegó a ser incómoda en muchos espacios de la sociedad de la época. Sin embargo, al sentirse acogido por la intención divina en virtud de su singular relación de identidad y confianza para con el Padre, Jesús mantiene a la hora de la muerte la esperanza radical de que su obra será legitimada y reivindicada de alguna manera (Moltmann, 2006).

Bajo estos presupuestos, la cruz pasa a ser un paso más en el camino que emprende el Hijo de Dios con miras al cumplimiento de su tarea. Entonces, los términos "fidelidad" y "radicalidad" brillan ahora con una luz renovada en cuanto la muerte no se impone como un designio divino que busca pagar el precio de un antiguo pecado (Borg y Crossan, 2007). Más bien, la muerte es el signo por excelencia de aquel que, siendo fiel al querer de quien lo envió, vive con radicalidad aceptando incluso las consecuencias más nefastas. Así, la cruz puede ser considerada punto culmen en la medida en que en ella se pone de manifiesto la entrega absoluta a un ideal que fue madurando en la historia personal de Jesús. Por eso, desligar la crucifixión de todo lo que la precedió sería abstraerla de la vida humana del Logos, convirtiéndola en un fetiche (Metz, 2007).

Ahora, si bien es cierto que se puede afirmar que Jesús presintió el final trágico que le esperaba, queda la pregunta abierta sobre si le atribuyó a su muerte algún tipo de significación expiatoria. Hay que tomar en cuenta que la reflexión paulina, que es la primera de la que se tiene noticia, resulta ser bastante posterior al acontecimiento del calvario (Rahner, 2007, pp. 300-301). Esto podría indicar que el trasfondo soteriológico de la muerte en la cruz sería producto de la interpretación de la comunidad pospascual, es decir, que respondería más a la realidad del Cristo de la fe que a la del Jesús histórico (Ratzinger, 2012).

Otro escollo que se debe señalar es la interpretación de la muerte de Jesús a la luz del concepto de sacrificio. En efecto, la manera clásica en la que las religiones entienden el sacrificio no encaja adecuadamente en el sistema de creencias del cristianismo (Varone, 1988). Pensar que se puede cambiar la actitud que tiene Dios hacia el ser humano, que, entre otras cosas, se presupone en muchas ocasiones como negativa, tiraría por tierra la fe en un Dios que es amor permanente 
y gratuito que realiza siempre el primer movimiento respecto del ser humano (Rahner, 2007, p. 331). Por eso, es necesario hacer una debida inteligencia del concepto para así armonizar tradición con analogía de la fe (Gesché, 2010).

\subsubsection{Resurrección}

La Resurrección de Jesús está unida intrínsecamente a su muerte: esta desemboca en aquella. Es el suceso por el cual, gracias a la perspectiva de la autocomunicación trascendental de Dios, se hace posible descubrir la realidad entera del salvador absoluto. Mediante la Resurrección, su misión queda confirmada dentro de la historia humana. Jesús es el profeta cuya palabra ha llegado a tener tal validez que llega a reunir en ella cualquier otra palabra. Por tal motivo, la Resurrección no puede ser pensada sencillamente como la revivificación biológica de un cuerpo físico. Su significación última debe ser entendida como la salvación definitiva de la existencia humana particular realizada por parte de Dios y ante Dios (Thiede, 2008).

Se puede comprender que hablar de Resurrección trasciende la frontera de lo temporal y se suscribe a lo concreto del presente:

La resurrección no significa el comienzo de un nuevo periodo de la vida de Jesús, llenado con algo nuevo, que lleve adelante el tiempo, sino precisamente la definitividad permanente y salvada de la única vida singular de Jesús, que precisamente a través de la muerte libre y obediente logró este permanente carácter definitivo de su vida. (Rahner, 2007, p. 13)

En consecuencia, el ser humano puede participar de esta Resurrección en la medida en que abra su existencia a Dios y permita que Él la acoja y la salve ya en la vivencia del hoy.

Redescubrir el sentido de la Resurrección conlleva repensar el concepto de eternidad, el cual se convierte en el fruto maduro del tiempo mismo. Una afirmación de tal naturaleza deja atrás la interpretación de que la eternidad es una larga duración incalculable que se experimenta más allá del tiempo propio de la vida mortal (Staniloae, 1984). Paralelamente, abre la puerta a entender la eternidad como una forma de espiritualidad y de libertad que le permiten al ser humano separarse del tiempo para entrar en una dinámica diferente:

Quien una vez ha tomado una decisión moralmente buena de vida y muerte, y la ha tomado en forma radical y sin atenuantes, de modo que de allí no salga para él más que la bondad aceptada de esta decisión 
misma, en ello ha experimentado ya aquella eternidad a la que nos referimos aquí. (Rahner, 2007, p. 320)

\section{Balance final}

Para ofrecer al lector algunos lineamientos en la construcción de la teología de la cruz en una cristología integral a partir de la teología de Rahner, el presente artículo contó, además de este balance final, con tres momentos principales. En el primero, se presentaron ciertas generalidades acerca de la figura del teólogo jesuita y sus intuiciones teológicas fundamentales para acercarse a su pensamiento. El segundo abordó en tres pasos las ideas más representativas de la cristología trascendental contenida en la obra Curso fundamental sobre la fe: introducción al concepto de cristianismo. El último momento consistió en la profundización de tres elementos que sirven como herramienta para la elaboración de una cristología integral.

Empero, por la naturaleza y por el propósito del trabajo, el artículo encuentra su principal limitación ante la experiencia pastoral de las comunidades cristianas. Es de reconocer que en varias ocasiones el lenguaje usado puede sonar extraño en ambientes ajenos a la racionalidad propia de la teología académica. Además, la carga especulativa que caracteriza la propuesta rahneriana a la hora de abordar la dogmática cristiana puede parecer un asunto que no tenga que ver con la cotidianidad de las comunidades de base, los grupos parroquiales y los cristianos en general.

Aun así, los límites mencionados pueden ser superados por las posibilidades del escrito, las cuales se apoyan en el camino de ida y vuelta que la experiencia cristiana debe recorrer. Es cierto que el primer momento de la fe está dado por la autocomunicación de Dios y su reconocimiento por parte del creyente. Pero esta vivencia debe llevar a la reflexión sobre sí misma, de tal modo que se elabore una conceptualización seria de aquello que se ha tenido como constitutivo del acto de creer (viaje de ida). Aquí encuadra el aporte de este trabajo, en cuanto él pretende ofrecer algunas herramientas que fortalezcan la edificación del armazón conceptual de la experiencia de Cristo. Es menester de posteriores disertaciones dilucidar los rasgos que, de manera más explícita, permitan al concepto enriquecer la vida cotidiana del creyente en lo concreto (viaje de vuelta).

Una de las principales posibilidades que tiene el acercamiento a la teología de Rahner consiste en la apertura cognoscitiva a partir de la diferenciación entre lo trascendental y lo categorial. La separación de ambas dimensiones, que se lleva 
a cabo solo en el ejercicio reflexivo y no en la realidad, permite repensar la comprensión del ser humano como sujeto histórico en relación con Dios. Así, mientras la historia acogida como guiada por una finalidad renueva la esperanza en una consumación que tendrá por objeto la inmediatez con Dios, la noción de un ser humano que es unidad de materia y espíritu ofrece nuevos caminos de estudio.

Las intuiciones acerca del cristianismo anónimo pueden llevarse más allá para llegar a tener nuevas luces respecto de la aceptación o negación de los dogmas y de la vivencia o del rechazo de las prácticas litúrgicas y de piedad. La pastoral de la Iglesia tendría así un nuevo punto de vista desde el cual plantear sus lineamientos, ya que su interés no sería, en primer momento, lograr la adhesión a una serie de estructuras dogmáticas, sino ofrecer caminos para que las personas se hagan responsables de su existencia y, en consecuencia, tengan experiencia del misterio sagrado. De lo anterior se desprende una actitud renovada abierta al diálogo que erradique la discriminación y facilite la relación con todos los que no confiesan el cristianismo católico de manera expresa.

Finalmente, la argumentación que se ofreció ante la cruz como consecuencia lógica de un acto de fidelidad y radicalidad se convierte en un punto clave para la interpelación del seguidor de Cristo hoy. Realmente, el compromiso cristiano no se limita a la adopción intelectual de un conjunto de proposiciones religiosas que tienen armonía entre ellas. Más bien, ha de ser la manifestación del encuentro vivo, real e indescriptible con la persona del resucitado que ya está posibilitado por la misma estructura interna de la persona. En palabras de Rahner, "la vida cristiana no es mero cumplimiento de normas generales, proclamadas por la Iglesia oficial, sino en ello y más allá de esto la llamada siempre singular de Dios, la cual, sin embargo, está mediada por el concreto encuentro amoroso con Jesús en una mística del amor" (p. 363).

\section{Referencias}

Abdelmalak, A. (2016). Haciéndose obediente hasta la muerte y una muerte de cruz: $R$. Guardini y H. U. von Balthasar ante el sentido teológico de la muerte en cruz de Jesucristo. Bogotá: Editorial Bonaventuriana.

Berríos, F. (2004). El método antropológico-trascendental de Karl Rahner como hermenéutica teológica del mundo y de la praxis. Teología y Vida, 45(1), 411-437. Doi: https://doi.org/10.4067/S0049-34492004000200011.

Borg, M. J. y Crossan, J. D. (2007). La última semana de Jesús: el relato día a día de la semana final de Jesús en Jerusalén. Madrid, España: PPC. 
Bueno de la Fuente, E. (1984). El cristianismo anónimo, momento constitutivo del proceso de integración teológica en el pensamiento de Karl Rahner. Burgense: Collectanea Scientifica, 25(1), 191-236.

Endean, P., Lehmann, K., Sobrino, J. y Wassilowsky, G. (2004). Karl Rahner: la actualidad de su pensamiento. Barcelona: Herder.

Gesché, A. (2010). El mal. Salamanca: Sígueme.

Gibellini, R. (1998). La teología del siglo XX. Santander: Sal Terrae.

Kilby, K. (2004). Karl Rahner: Theology and philosophy. Londres, RU: Routledge. Doi: https://doi.org/10.4324/9780203505007

Ludlow, M. (2000). Universal salvation: Eschatology in the thought of Gregory of Nyssa and Karl Rahner. Oxford: Oxford University Press. Doi: https://doi. org/10.1093/0198270224.001.0001

Metz, J. (2002). Dios y tiempo: nueva teología política. Madrid, España: Trotta.

Metz, J. (2007). Memoria passionis: una evocación provocadora en una sociedad pluralista. Santander, España: Sal Terrae.

Metz, J. (2013). Por una mística de ojos abiertos: cuando irrumpe la espiritualidad. Barcelona, España: Herder.

Metz, J. y Rahner, K. (1979). Invitación a la oración: solidaridad en el dolor y el compromiso. Santander, España: Sal Terrae.

Moltmann, J. (1992). ¿Qué es teología hoy? Dos contribuciones para su actualización. Salamanca, España: Sígueme.

Moltmann, J. (2006). Teología de la esperanza. Salamanca, España: Sígueme.

Moltmann, J. (2010). El Dios crucificado: la cruz de Cristo como base y crítica de la teología cristiana. Salamanca, España: Sígueme.

Piug, A. (2006). Jesús: una biografía. Barcelona, España: Destino.

Rahner, K. (2007). Curso fundamental sobre la fe: introducción al concepto de cristianismo. Barcelona, España: Herder.

Ratzinger, J. (2008). Jesús de Nazaret. Bogotá, Colombia: Planeta.

Ratzinger, J. (2012). Jesús de Nazaret: desde la entrada en Jerusalén hasta la Resurrección. Madrid, España: Encuentro.

Ruiz de la Peña, J. (1996). La pascua de la creación: escatología. Madrid, España: Biblioteca de Autores Cristianos.

Saldaña Mostajo, M. (2013). Rutina habitada: vida oculta de Jesús y cotidianidad creyente. Santander, España: Sal Terrae.

Schickendantz, C. (2004). El "Curso fundamental de la fe" de Karl Rahner: objetivo, génesis y significado de un "experimento". Teología y Vida, 45(1), 137-156. Doi: https://doi.org/10.4067/S0049-34492004000100007 
Staniloae, D. (1984). Dios es amor. Salamanca, España: Secretariado Trinitario.

Thiede, W. (2008). El sentido crucificado: una teodicea trinitaria. Salamanca, España: Sígueme.

Varone, F. (1988). El dios "sádico": ¿ama Dios el sufrimiento? Santander, España: Sal Terrae. 